\title{
Pulsed ultrasound enhances the delivery of nitric oxide from bubble liposomes to ex vivo porcine carotid tissue
}

This article was published in the following Dove Press journal:

International Journal of Nanomedicine

6 October 2014

Number of times this article has been viewed

\author{
JT Sutton' \\ JL Raymond' \\ MC Verleye ${ }^{2}$ \\ GJ Pyne-Geithman ${ }^{3}$ \\ CK Holland ${ }^{4}$
}

'University of Cincinnati, Biomedical Engineering Program, Cincinnati, $\mathrm{OH}$, ${ }^{2}$ University of Notre Dame

Department of Chemical Engineering, Notre Dame, IN, ${ }^{3}$ University of Cincinnati, College of Medicine, Department of Neurosurgery and the University of Cincinnati Neuroscience Institute, and Mayfield Clinic, Cincinnati, OH, ${ }^{4}$ University of Cincinnati, College of Medicine, Internal Medicine, Division of Cardiovascular Diseases, Cincinnati, OH, USA
Correspondence: JT Sutton

University of Cincinnati, Cardiovascular

Center, CVC 3940, Cincinnati, $\mathrm{OH}$

45267-0586, USA

Tel +I $5 \mid 35585505$

Fax + I 5135586102

Email suttonjt@mail.uc.edu
Abstract: Ultrasound-mediated drug delivery is a novel technique for enhancing the penetration of drugs into diseased tissue beds noninvasively. By encapsulating drugs into microsized and nanosized liposomes, the therapeutic can be shielded from degradation within the vasculature until delivery to a target site by ultrasound exposure. Traditional in vitro or ex vivo techniques to quantify this delivery profile include optical approaches, cell culture, and electrophysiology. Here, we demonstrate an approach to characterize the degree of nitric oxide (NO) delivery to porcine carotid tissue by direct measurement of ex vivo vascular tone. An ex vivo perfusion model was adapted to assess ultrasound-mediated delivery of NO. This potent vasodilator was coencapsulated with inert octafluoropropane gas to produce acoustically active bubble liposomes. Porcine carotid arteries were excised post mortem and mounted in a physiologic buffer solution. Vascular tone was assessed in real time by coupling the artery to an isometric force transducer. NO-loaded bubble liposomes were infused into the lumen of the artery, which was exposed to $1 \mathrm{MHz}$ pulsed ultrasound at a peak-to-peak acoustic pressure amplitude of $0.34 \mathrm{MPa}$. Acoustic cavitation emissions were monitored passively. Changes in vascular tone were measured and compared with control and sham NO bubble liposome exposures. Our results demonstrate that ultrasound-triggered NO release from bubble liposomes induces potent vasorelaxation within porcine carotid arteries (maximal relaxation $31 \% \pm 8 \%$ ), which was significantly stronger than vasorelaxation due to NO release from bubble liposomes in the absence of ultrasound (maximal relaxation $7 \% \pm 3 \%$ ), and comparable with relaxation due to $12 \mu \mathrm{M}$ sodium nitroprusside infusions (maximal relaxation $32 \% \pm 3 \%$ ). This approach is a valuable mechanistic tool for assessing the extent of drug release and delivery to the vasculature caused by ultrasound.

Keywords: ultrasound-mediated drug delivery, bubble liposomes, nitric oxide

\section{Introduction}

\section{Ultrasound-mediated drug delivery}

Ultrasound has been investigated as a method for triggering enhanced drug delivery within the human vasculature. This technique is broadly appealing, given the potential of ultrasound to control drug delivery spatially and temporally in a noninvasive manner. Ultrasound-mediated drug delivery (UMDD) has been demonstrated in a number of tissue beds, including the blood-brain barrier, cardiac tissue, prostate, and large arteries.

Acoustic cavitation is a physical mechanism that is hypothesized to mediate UMDD. ${ }^{1-4}$ Cavitation refers to nonlinear bubble activity that occurs within the vasculature upon ultrasound exposure and can exert mechanical stress on nearby cells and junctions. Mechanical stress can trigger the reduction of barriers to drug delivery, such 
as endothelial tight junctions or phospholipid membranes, via transient permeabilization. Cavitation can be nucleated at moderate peak-to-peak acoustic pressure amplitudes $(<1 \mathrm{MPa})$ by ultrasound contrast agents. ${ }^{5-8}$

Nitric oxide (NO) is a molecule that plays a mechanistic role in UMDD. A potent vasodilating gas, NO is involved in the regulation of paracellular and transcellular transport pathways, ${ }^{1,9}$ and is implicated as a regulatory promoter of hyperpermeability. ${ }^{3,10}$ Attenuation of NO production in the etiology of progression ${ }^{5,11}$ of atherosclerosis and diabetic vascular disease $e^{1,2,12-14}$ further highlights the need for novel therapeutic NO modulation and delivery strategies.

\section{Drug delivery quantification}

Strategies to study ultrasound-mediated drug release and delivery in vitro and ex vivo have involved optical and electrophysiological techniques. ${ }^{3,4,15-19}$ Optical techniques, such as fluorescence ${ }^{16,20,21}$ or luminescence, ${ }^{18,22,23}$ take advantage of the native optical properties of the therapeutic or conjugation of tracer molecules. Electrophysiological approaches, such as voltage-clamp techniques, ${ }^{19,24,25}$ directly assess the changes in membrane potential provoked during UMDD, but often require isolated cells cultured in vitro, where cellular processes can vary from in vivo conditions. ${ }^{26-28}$ In vivo animal models of UMDD provide relevant bioeffect information, but are costly and subject to considerable intersubject variability. The ability to detect and monitor the response of intact, isolated vascular tissue in real time would constitute a significant advancement in the study of UMDD.

Isolated tissue bath perfusion systems have been used extensively to characterize contractility changes induced by a therapeutic $c^{20,29-33}$ in a variety of muscular tissue beds, including gastric, ${ }^{1,2,12-14}$ peripheral vascular, $3,4,15-19$ and cardiovascular ${ }^{16,20,21}$ beds. In these systems, dosedependent changes in active muscular tension can be characterized in response to vasorelaxing agents such as bradykinin, ${ }^{18,22,23}$ sodium nitroprusside, ${ }^{19,24,25}$ nitroglycerin, ${ }^{26-28}$ and NO. ${ }^{20,29-33}$ Adaptation of the isolated tissue bath model to drug delivery studies could provide relevant, real-time quantitative data on the drug release and delivery profiles triggered by ultrasound. We hypothesize that these isolated tissue bath systems can be used to characterize NO-mediated changes in carotid vascular tone upon ultrasound exposure.

\section{Materials and methods}

\section{Tissue bath system}

Due to their similarity to human arteries, ease of excision, and robust post mortem viability, ${ }^{31}$ porcine carotid arteries were chosen as the model artery to study NO delivery. Carotid arteries were obtained post mortem from young Yorkshire pigs $(\sim 20 \mathrm{~kg})$ according to a protocol approved by the Institutional Animal Care and Use Committee at the Cincinnati Department of Veterans Affairs Medical Center (Animal Welfare Assurance Number A3446-01). Seven pigs were initially anesthetized with intravenous ketamine $30 \mathrm{mg} / \mathrm{kg}$, followed by pentobarbital $35 \mathrm{mg} / \mathrm{kg}$ for deep surgical anesthesia. Prior to artery excision, the animals were euthanized with saturated $\mathrm{KCl}$ solution $\left(\sim[\mathrm{KCl}]_{\text {in vivo }}\right.$ $0.18 \mathrm{M}$ ). Segments of porcine carotid tissue were harvested immediately following sacrifice and stored in ice-cold, oxygenated Krebs-Henseleit buffer (KHB, NaCl 115.9 mM; KCl $5.4 \mathrm{mM} ; \mathrm{MgSO}_{4}-7 \mathrm{H}_{2} \mathrm{O} 1.2 \mathrm{mM}$; $\mathrm{NaHCO}_{3} 25 \mathrm{mM}$; D-glucose $11.1 \mathrm{mM}$; $\mathrm{NaH}_{2} \mathrm{PO}_{4} 0.5 \mathrm{mM}$ ) until use within 18 hours of excision from the animal. Previous investigators ${ }^{32}$ have suggested that arteries remain viable for up to 3 days if obtained and handled in this manner. The tissue was dissected free of loose adventitia and connective tissue, and segmented into rings. These rings were cut to a length between $3.95 \mathrm{mM}$ and $4.05 \mathrm{mM}$; the mean wet mass after blotting was $20.5 \mathrm{mg}$ with a standard deviation of $2.6 \mathrm{mg}$. Each segment was mounted on two rigid, stainless-steel wires. The bottom wire was fixed to the tissue bath, and the top wire was coupled to an isometric force transducer (Radnoti LLC, Monrovia, CA, USA) for measurement of arterial tension. The electronic configuration is depicted in Figure 1. The tension signal was sampled digitally at $20 \mathrm{~Hz}$ (LabChart 6; AD Instruments, Colorado Springs, CO, USA) and saved to a PC for post-processing. The carotid segment was submerged in a custom reservoir filled with KHB maintained at physiologic temperature with continuous bubbling of a $95 \% \mathrm{O}_{2} / 5 \% \mathrm{CO}_{2}$ gas mixture to maintain physiologic $\mathrm{pH}$ (range 7.35-7.45).

Following mounting of the artery and submersion in physiologic KHB, healthy arteries underwent a brief contraction and relaxation cycle. ${ }^{32}$ Artery rings not exhibiting this behavior were deemed unfit for experimentation and discarded. Prior to treatment, the arterial ring was prestretched to relieve the passive elastic component of arterial tension in a manner similar to that described by Herlihy and Murphy. ${ }^{32}$ Briefly, the artery was stretched incrementally by translating the force transducer with a micropositioning stage (Radnoti LLC). To equilibrate the artery within physiologic buffer, the artery was alternately contracted and relaxed by serial infusions of KHB and KHB containing additional $\mathrm{KCl}$, substituted in an equimolar fashion for $\mathrm{NaCl}$. $\mathrm{KCl}$ was chosen as the optimal contractile agent in this biomedical engineering study due to its ability to induce rapid smooth 


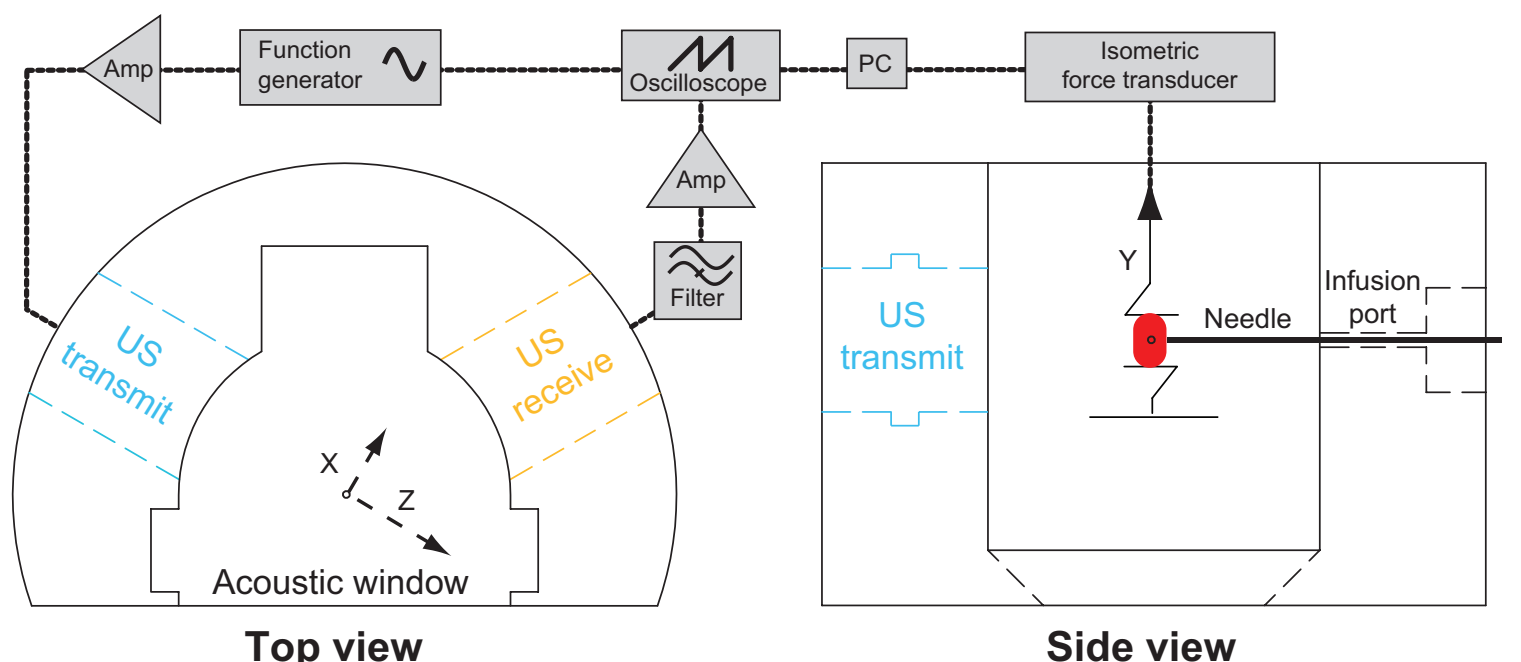

Figure I Electronic configuration of the ultrasound tissue bath system.

Notes: Two submersible ultrasound transducers are coupled to the reservoir: a transmit transducer (I MHz, $3 \%$ duty cycle, blue) focuses on the lumen of the artery, while a second receive transducer $(7 \mathrm{MHz}$, orange) detects cavitation emissions from nitric oxide-loaded bubble liposomes perfused within the vessel lumen (red) via a 26 -gauge blunt injection needle.

Abbreviation: US, ultrasound.

muscle constriction consistently across carotid arteries excised from different pigs of the same breed. Each artery was contracted initially to steady state using KHB containing $50 \mathrm{mM} \mathrm{KCl}$ after each increment. Following a KHB wash, this process was repeated until a maximum $\mathrm{KCl}$ contraction was achieved. Healthy arteries consistently responded to precontraction with $50 \mathrm{mM} \mathrm{KCl}$-doped KHB; however, the extent of precontraction was variable (range $200-330 \mathrm{mN}$ ). The basal ring tension that produced a maximum contraction tension was determined to be $75 \mathrm{mN}$. Thus, subsequent rings were manually prestretched to this basal tension upon mounting.

\section{Bubble liposomes}

Bubble liposomes were manufactured according to the method described by Endo-Takahashi et $\mathrm{al}^{34}$ for bubble liposomes. This liposomal formulation consisted of dipalmitoylphosphatidylcholine (DPPC), N-[1-(2,3-dioleoyloxy) propyl]-N,N,N-trimethylammonium (DOTAP), polyethylene glycol (PEG) 2000, and PEG 750 in a 79:15:3:3 molar ratio. After manufacturing, $1 \mathrm{~mL}$ (1 mg lipid) of the liposomal emulsion was pipetted into glass vials, which were evacuated of headspace air with a laboratory vacuum and stored at $4^{\circ} \mathrm{C}$ until use. Immediately prior to use, the vials were warmed to room temperature and $2.5 \mathrm{~mL}$ of gas was injected into the vial headspace through a rubber septum. For NOloaded bubble liposomes (NOBLs), this gas consisted of a 50:50 volume ratio of NO gas (Sigma-Aldrich, St Louis, MO, USA) and octafluoropropane $\left(\mathrm{C}_{3} \mathrm{~F}_{8}\right.$, or OFP) gas (Specialty Gases of America, Toledo, OH, USA). To assess the effect of cavitation alone (without $\mathrm{NO}$ ) on vasorelaxation, $\mathrm{C}_{3} \mathrm{~F}_{8}$ bubble liposomes were also manufactured by injecting $2.5 \mathrm{~mL}$ of $\mathrm{C}_{3} \mathrm{~F}_{8}$. Following this step, the vial was mechanically agitated by shaking vigorously for 45 seconds (Vialmix ${ }^{\circledR}$, Lantheus Medical Imaging, North Billerica, MA, USA). This agitation step heated the emulsion slightly, so the vial was allowed to equilibrate to room temperature. Immediately prior to experimental use, $500 \mu \mathrm{L}$ of the liposomal emulsion was diluted into oxygenated $\left(\mathrm{pO}_{2}: 722 \mathrm{mmHg}\right.$ ) room temperature $\mathrm{KHB}$ to a final concentration of $0.05 \mathrm{mg}$ lipid $/ \mathrm{mL}$ for infusion into the system.

\section{NOBL characterization}

A sample of the NOBL suspension was diluted $(1: 1000 ; \mathrm{v} / \mathrm{v})$ into room temperature, aerated phosphate-buffered saline (Sigma-Aldrich) and the size distribution was measured using an impedance-based particle sizer (Multisizer 4, $30 \mu \mathrm{m}$ aperture; Beckman Coulter, Brea, CA, USA). Each measurement analyzed $100 \mu \mathrm{L}$ of the diluted sample through a $30 \mu \mathrm{m}$ aperture over 30 seconds. Each measurement produced a number density histogram, corrected for the dilution, with bins logarithmically spaced between $0.6 \mu \mathrm{m}$ and $18 \mu \mathrm{m}$. This histogram was transformed into a volume-weighted distribution for further analysis. The results from three measurements, each using a fresh vial of NOBLs, were averaged to produce a final volume-weighted size distribution.

The frequency-dependent attenuation coefficient, $\alpha(\mathrm{f})$ in $\mathrm{dB} / \mathrm{cm}$, was determined using a broadband substitution technique, ${ }^{35}$ the components of which were described 
previously in Raymond et al. ${ }^{36}$ Briefly, NOBLs were diluted (1:500) into a reservoir containing aerated phosphate-buffered saline, stirred, and allowed to flow by gravity into a sample chamber with acoustically transparent polycarbonate film windows (CLINIcell 25, Mabio, Tourcoing, France). The reservoir, sample chamber, and transducers were mounted in a test tank filled with distilled water maintained at $37^{\circ} \mathrm{C} \pm 0.5^{\circ} \mathrm{C}$ using a circulating water bath (Neslab EX, Newington, NH, USA). A pair of broadband transducers (PI-20, Olympus NDT, Waltham, MA, USA) was used to acquire the throughtransmission spectrum over the frequency range of $1-30 \mathrm{MHz}$ (31 KPa peak negative pulse pressure; $33 \mathrm{~dB}$ dynamic range). The attenuation spectrum was computed from the received amplitude spectra in the absence (diluent alone) and presence of the bubble liposomes, respectively. Acoustic attenuation measurements were made in triplicate and a separate vial of NOBLs was used for each measurement.

\section{Hemoglobin}

The short half-life ( $<1$ second) of NO in the presence of hemoglobin and oxygen in vivo limits the spatial extent over which $\mathrm{NO}$ can be effective as a signaling molecule. ${ }^{37}$ In order to mimic the in vivo milieu more closely and to quench nonencapsulated NO, 1 g/L hemoglobin (porcine, SigmaAldrich) was added to the reservoir prior to each treatment. We observed that hemoglobin concentrations greater than $1 \mathrm{~g} / \mathrm{L}$ produced a negligible decrease in vasorelaxation during NOBL + KHB infusions and occasionally caused vasospasmic contractions. Thus, $1 \mathrm{~g} / \mathrm{L}$ hemoglobin was used in all subsequent treatments.

\section{Ultrasound exposure and cavitation detection}

To reveal the mechanism of ultrasound-mediated drug release and delivery of NO to vascular tissue, two ultrasound transducers were coupled to the tissue bath reservoir. One transducer was used to deliver pulsed ultrasound to nucleate cavitation from the liposomes and a second transducer was used to monitor the acoustic emissions passively for evidence of acoustic cavitation. The experimental configuration is depicted in Figure 1. Prior to each experiment, a calibrated $1 \mathrm{MHz}$ therapy transducer (Olympus Panametrics, Waltham, MA, USA) was aligned confocally with a $7.5 \mathrm{MHz}$ passive cavitation detector (PCD; Olympus Panametrics) using an ultrasonic pulser receiver (5077PR; Olympus NDT). The confocal point was positioned in the axial center of the carotid ring using a three-axis translation stage (Newport 423,
Irvine, CA, USA). This geometry was chosen to ensure that the ultrasound therapy field encompassed the entire carotid artery, while cavitation emissions were detected primarily from the lumen. During experimental treatment, a function generator (Agilent Technologies, Santa Clara, CA, USA) supplied a sinusoidal signal (30 cycles, $100 \mathrm{~Hz}$ pulse repetition frequency) that was amplified (750A250; Amplifier Research, Souderton, PA, USA) and used to drive the $1 \mathrm{MHz}$ therapy transducer. Acoustic scattering within the tissue bath reservoir affected the beam profile slightly. Therefore, an in situ pressure field calibration was performed in the absence of the artery ring and wires (Figure 2).

During ultrasound exposure, acoustic emissions were detected by the PCD, high-pass filtered (1 MHz high-pass, \#07766 TTE, Los Angeles, CA, USA), amplified (10×, Model 5185, Signal Recovery, Oak Ridge, TN, USA), and sampled at $20 \mathrm{MHz}$ with an oscilloscope (LeCroy Model LT372, Chestnut Ridge, NY, USA). Sequences of 128 voltage time traces were saved to a PC for post-processing (Figure 3A). To enable cavitation detection spaced more consistently in time, one of every four pulses was saved. The traces were analyzed using a custom MatLab (The Mathworks Inc, Natick, MA, USA) script to extract spectral information associated with specific modes of bubble activity. A window (Blackman window, MatLab) was applied to each scattered pulse (Figure 3B) and transformed into the frequency domain. Each frequency spectrum was scaled to account for the energy lost due to windowing. A frequency domain comb filter was applied to the power spectrum (Figure $3 \mathrm{C}$ ) to extract the ultraharmonic $(100 \mathrm{kHz}$ bands at odd multiples of $500 \mathrm{kHz}$ ) and broadband

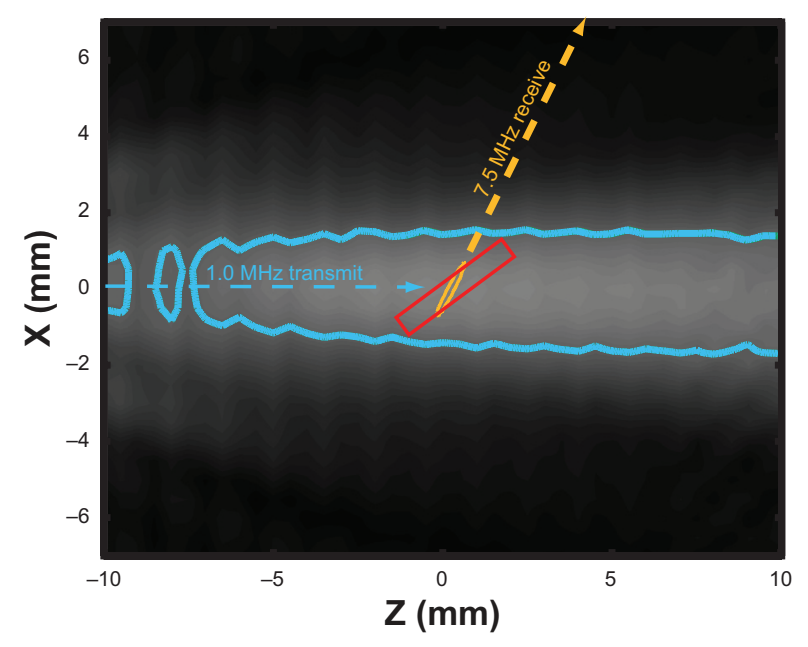

Figure 2 In situ ultrasound beam profiles of the I $\mathrm{MHz}$ and $7.5 \mathrm{MHz}$ transducers. Notes: The $-3 \mathrm{~dB}$ contours of the transmit field (blue) and receive sensitivity (orange) are depicted, along with the anticipated location of the artery (red, box). 

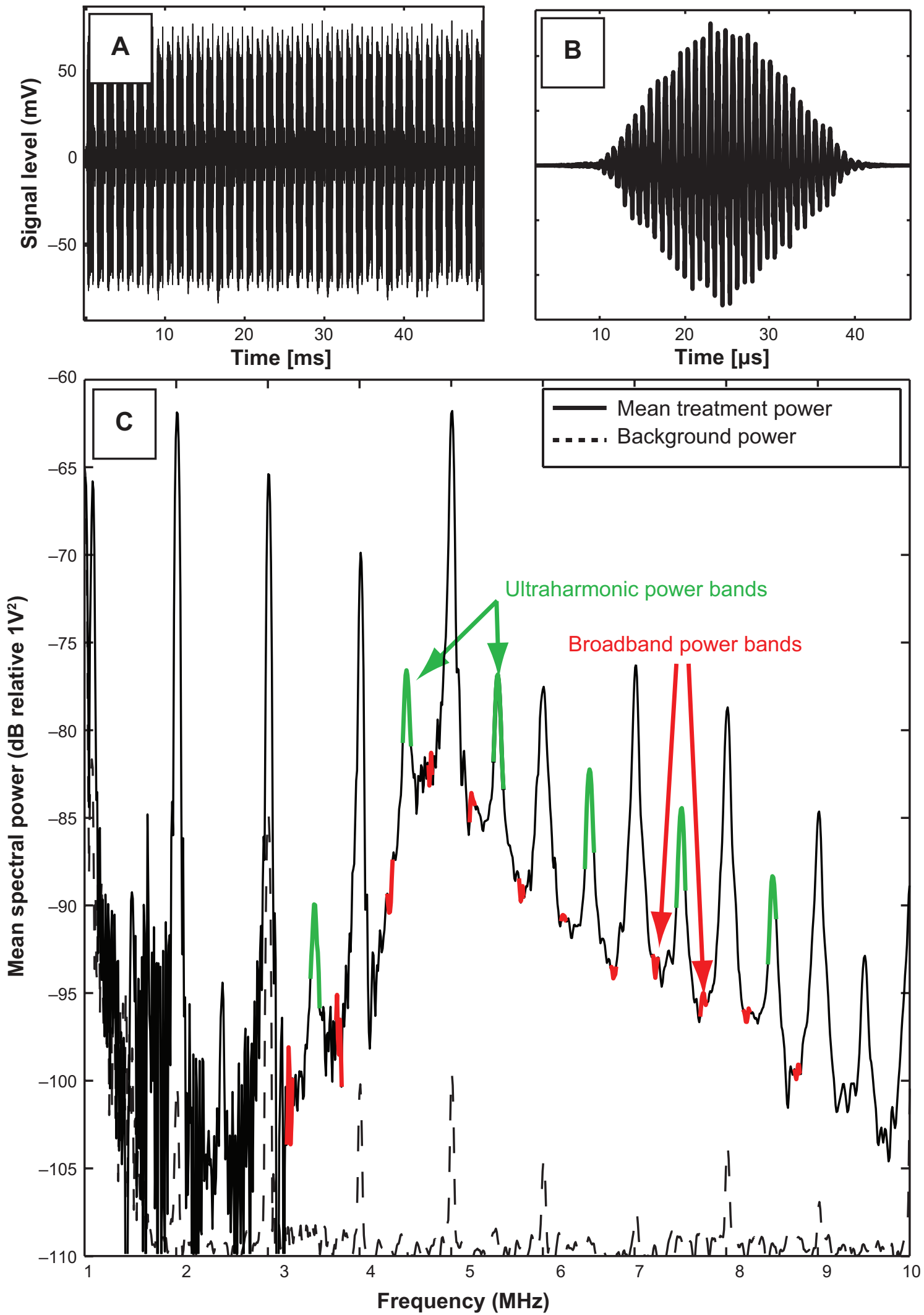

Figure 3 Graphical representation of the signal processing technique used to assess cavitation emissions detected by the single element passive cavitation detector. Notes: (A) Scattered pulses detected by the passive cavitation detector were filtered (I MHz low pass filter), amplified (I0X), digitized, and saved to a PC in sequence mode. Individual pulses were windowed in the time domain (B), and then transformed into the frequency domain. Ultraharmonic and broadband components of the power spectrum (C) were quantified, and served as indicators of stable and inertial cavitation, respectively. 
( $50 \mathrm{kHz}$ bands between harmonic and ultraharmonic frequencies) components of the spectrum. The energy contained in the ultraharmonic and broadband signals was associated with stable and inertial cavitation, respectively. ${ }^{38,39}$ This process is depicted graphically in Figure 3.

Ultrasound parameters were chosen to promote stable cavitation nucleated by the NOBLs within the lumen of the arterial ring over the 55-second treatment. A 30-cycle therapy pulse was chosen to minimize standing waves in the reservoir. To determine the optimal acoustic pressure to promote stable cavitation, a dose-escalation approach was employed. An artery was mounted within the reservoir filled with oxygenated KHB containing $1 \mathrm{~g} / \mathrm{L}$ hemoglobin. NOBL infusions $(0.2 \mathrm{~mL} / \mathrm{min})$ with concurrent ultrasound exposure and cavitation detection were performed serially. Between each treatment, the reservoir was flushed with fresh hemoglobin-doped KHB and the acoustic pressure increased incrementally. This process was repeated at peakto-peak acoustic pressure amplitudes ranging from $0 \mathrm{MPa}$ to $0.38 \mathrm{MPa}$. The peak-to-peak acoustic pressure amplitude that promoted maximal ultraharmonic energy over the 50 -second ultrasound exposure (0.34 MPa) was chosen for all subsequent exposures.

\section{Treatment}

During treatment, the lumen of each artery was infused for 55 seconds with randomized combinations of buffer alone, buffer with NOBLs, or buffer with $12 \mu \mathrm{M}$ sodium nitroprusside (Sigma-Aldrich) using a 24-gauge blunt hypodermic needle connected to a syringe pump (KD Scientific, \#23; Canning Vale, Australia). After 5 seconds of infusion, ultrasound or sham exposure and cavitation detection commenced. This experimental procedure is diagrammed in Figure 4.

\section{Tension analysis}

Arterial ring tension was analyzed using a custom MatLab script. Each tension curve was normalized to the maximum tension produced by $50 \mathrm{mM} \mathrm{KCl} \mathrm{KHB}$ using Equation 1,

$$
\% \text { Relaxation }=\frac{T_{M A X}-T(t)}{T_{M A X}-T_{B A S A L}}
$$

where $T_{M A X}$ is the initial tension produced by $\mathrm{KCl}$ contraction, $T(t)$ is the arterial tension as a function of time, and $T_{B A S A L}$ is the basal tension after manual stretching $(75 \mathrm{mN})$. A representative tension curve for each treatment is given in Figure 5. For each treatment, the minimum value percent relaxation, ie, maximal relaxation, was used to compare across treatment groups. This metric has been used previously to compare treatments in NO-related vascular tension studies. ${ }^{40}$

\section{Statistical analyses}

In general, the mean and standard deviation of each data set was reported. Statistical analyses were performed using MatLab (Statistical Toolbox). Normal distributions were confirmed using Lilliefors test, with a threshold $P$-value of 0.05 . Differences in means between treatment groups were analyzed using a one-way unbalanced analysis of variance. $P$-values less than 0.05 were considered to be statistically significant. Subsequently, pairwise comparisons with a Bonferroni correction were performed to compare across individual treatments to minimize the family-wise error rate for multiple comparisons.

Linear regression was performed to test for a correlation between maximal relaxation and (a) wet tissue weight, (b) $35 \mathrm{mM} \mathrm{KCl}$ tension, and (c) cavitation energy. A one-way unbalanced analysis of variance was used to test for significant correlations. For these tests, the $P$-value, f-statistic $\left(\mathrm{F}_{\text {stat }}\right)$, and degrees of freedom (df) are reported. Spearman's rank correlation coefficients $(\rho)$ were computed to test for monotonic statistical relationships. The null hypothesis of no correlation was tested to produce a $P$-value; values below 0.05 were considered to be statistically significant.

\section{Results}

\section{Liposome characterization}

As depicted in Figure 6A, NOBLs had a broad, bimodal volume-weighted size distribution, ranging in diameter from

\begin{tabular}{|c|c|cl|}
\hline \multicolumn{2}{|c|}{ Artery preparation } & \multicolumn{1}{c|}{ Experimental treatment } \\
\hline Artery equilibration & $\begin{array}{c}\text { Hemoglobin (1 g/L) } \\
\text { added to reservoir }\end{array}$ & $\begin{array}{c}\text { Ultrasound } \\
\text { exposure }\end{array}$ & $\begin{array}{l}\text { Cavitation } \\
\text { detection }\end{array}$ \\
$\begin{array}{c}\text { Tension } \\
\text { measurement }\end{array}$ & $\mathrm{KCl}$ contraction & Treatment infusion \\
\hline
\end{tabular}

Figure 4 Timeline of procedures performed during a typical experimental exposure.

Notes: Repeated measurements were made in series following $35 \mathrm{mM}$ potassium chloride washes, followed by tension equilibration. 


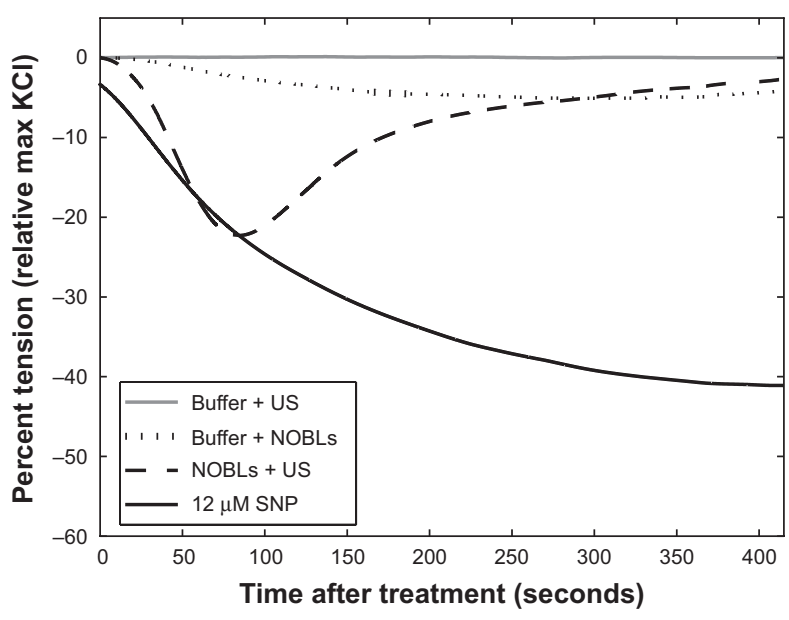

Figure 5 Representative tension reduction (relative to the maximum $\mathrm{KCl}$ contraction tension) for buffer + US, buffer + NOBLs, NOBLs + US (peak-to-peak acoustic pressure amplitude $0.34 \mathrm{MPa}$ ), and control agonist sodium nitroprusside. Each treatment's minimum tension (maximal relaxation) was used for grouped analysis.

Abbreviations: SNP, sodium nitroprusside; NOBLs, nitric-oxide loaded bubble liposomes; US, ultrasound.

approximately $1.5 \mu \mathrm{m}$ to $15 \mu \mathrm{m}$. The peak volume density occurred at a diameter of $2.5 \mu \mathrm{m}$. A separate population of particles existed at $11 \mu \mathrm{m}$, diminishing in diameter above $15 \mu \mathrm{m}$.

Figure 6B shows the measured attenuation coefficient as a function of frequency for NOBLs $(n=3)$. NOBLs attenuated ultrasound across the $33 \mathrm{~dB}$ bandwidth of the system (1-30 MHz). A strong, broad resonance peak $(\alpha=13.0 \mathrm{~dB} / \mathrm{cm})$ was observed at $5 \mathrm{MHz}$. A second resonance peak $(\alpha=12.3 \mathrm{~dB} / \mathrm{cm})$ was observed near $28 \mathrm{MHz}$. NOBLs attenuated weakly between these two frequencies.

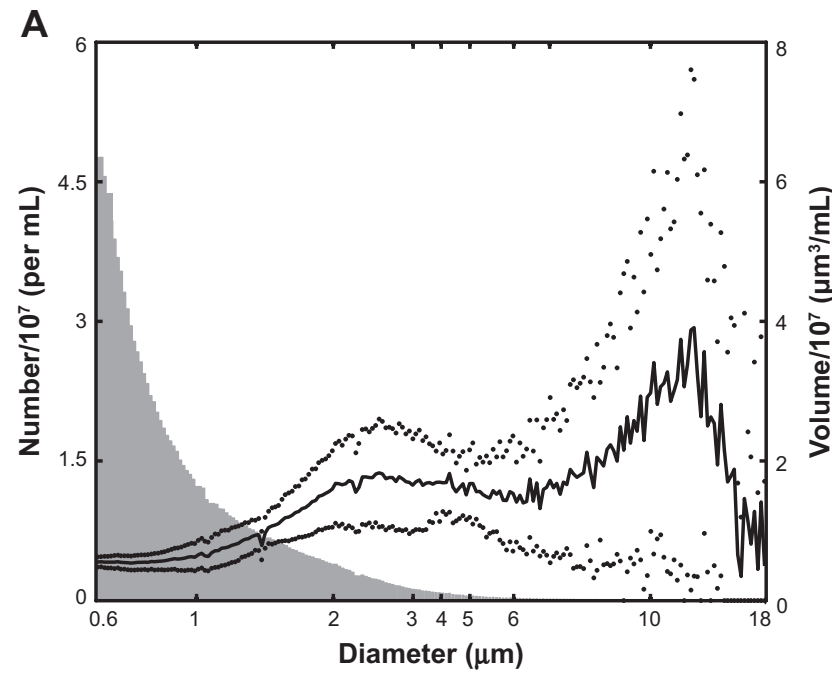

\section{Cavitation}

In general, ultraharmonic and broadband acoustic emissions within the arterial lumen persisted throughout the 50 -second exposures in all eight ultrasound-treated arteries. Figures 7A and $\mathrm{B}$ show representative traces of the ultraharmonic and broadband acoustic power detected by the PCD as a function of time. A representative spectrum, averaged over the 55-second treatment, is depicted in Figure 3C. Ultraharmonic energy was typically strong, yet variable, during the first few seconds of ultrasound exposure, and remained steady for the duration of the 50-second exposure. Within the NOBL + ultrasound treatment group, no correlation was observed between maximal relaxation and the average spectral emissions (ultraharmonic, $\rho=-0.45, P=0.21$; harmonic, $\rho=-0.46, P=0.25$; broadband, $\rho=-0.50, P=0.21$ ).

\section{Vasorelaxation}

Seven carotid rings each from seven separate pigs were exposed to each experimental treatment, as shown in Figure 8. Carotid rings relaxed in response to treatments in a characteristic manner, ie, a sharp tension decrease followed by steady restoration to the tension level induced by $35 \mathrm{mM} \mathrm{KCl}$ precontraction. Neither the order of treatment nor the time postexcision from the animal $(\rho=-0.45, P=0.21)$ resulted in an apparent trend in maximal relaxation. Relaxation after $12 \mu \mathrm{M}$ sodium nitroprusside infusions was significantly stronger $(32 \% \pm 5 \%)$ than NOBL infusions $\left(P<0.01, \mathrm{~F}_{\text {stat }}=104.15, \mathrm{df}\right.$ $=13$ ) and sham control treatments, which consisted of buffer and NOBLs $(7 \% \pm 3 \%)$, buffer and ultrasound $(1 \% \pm 2 \%)$, or $\mathrm{C}_{3} \mathrm{~F}_{8}$ bubble liposomes and ultrasound exposure $(2 \% \pm 1 \%)$. Arterial rings exposed to NOBLs + ultrasound experienced

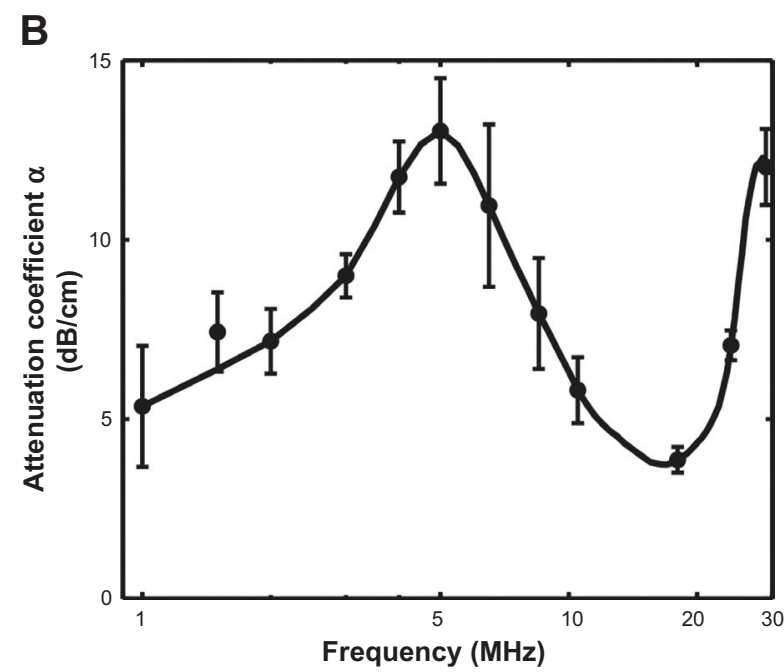

Figure 6 (A) Size distribution $(n=3)$ of the NOBLs, weighted by volume (black) and number density (gray).

Notes: The presence of particles $>4 \mu \mathrm{M}$ (by volume) agrees with Endo-Takahashi et al. ${ }^{34}$ Dots indicate one standard deviation. (B) Acoustic attenuation as a function of frequency, as determined using the system described in Raymond et al. ${ }^{36}$ 


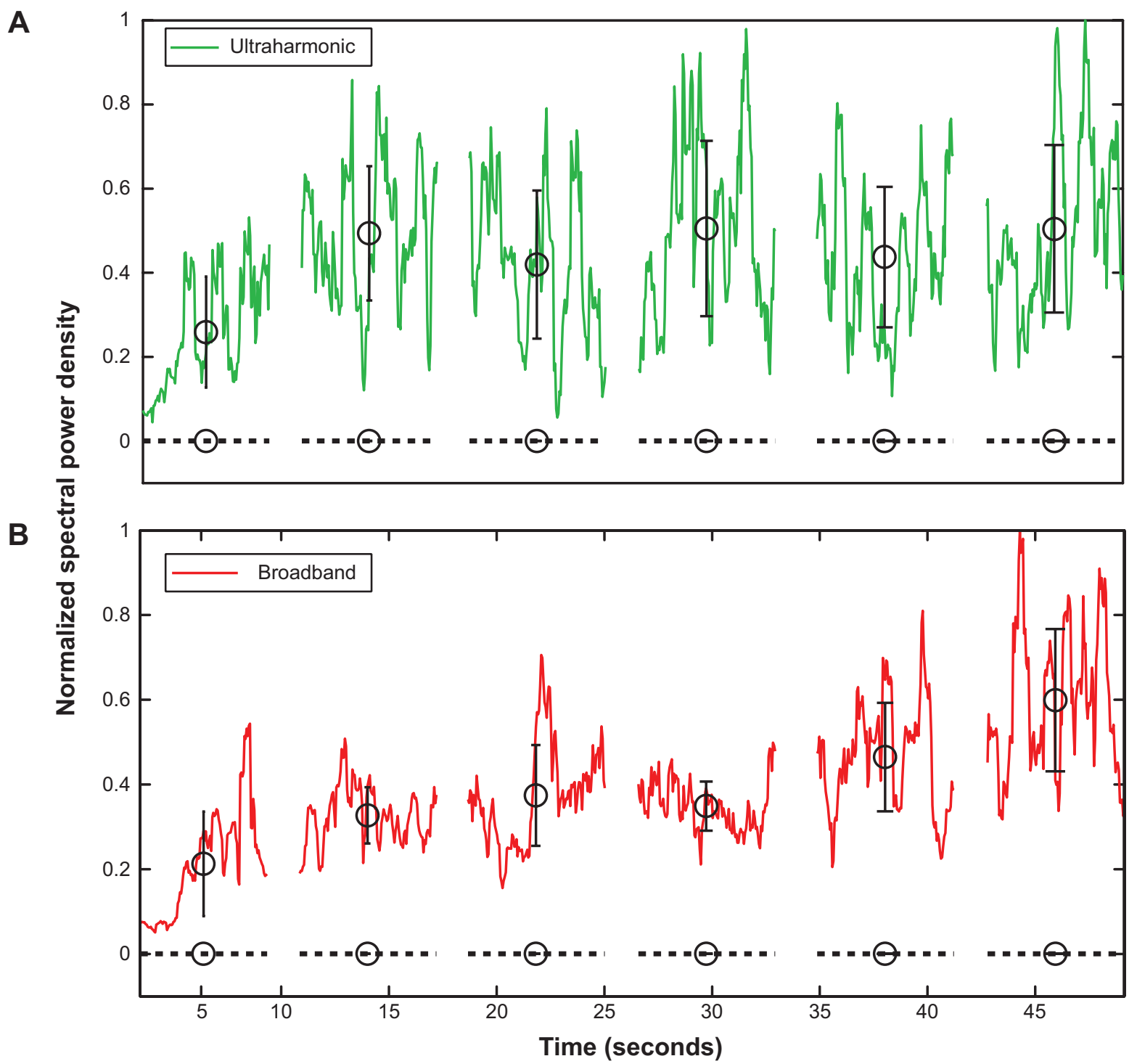

Figure 7 Spectral analysis of scattered acoustic signal from NOBLs.

Notes: Averaged spectrum of detected cavitation emissions across a 50-second ultrasound exposure during NOBL infusion into the lumen of a carotid artery (solid), compared to spectral emission from sham ultrasound exposures (buffer + ultrasound alone, dotted). (A) Ultraharmonic (eg, 3f/2, 5f/2.) and (B) broadband frequency components of the transmitted fundamental frequency $(\mathrm{f}, \mathrm{I} \mathrm{MHz})$ were consistently observed, indicating strong, persistent nonlinear bubble activity. Black circles indicate the mean of the local data group, bars indicate \pm one standard deviation.

Abbreviation: NOBLs, nitric oxide-loaded bubble liposomes.

strong maximal relaxation $(31 \% \pm 8 \%)$ that was significantly greater than buffer and NOBLs $\left(P<0.001, \mathrm{~F}_{\text {stat }}=29.01\right.$, $\mathrm{df}=13)$ and statistically identical to treatment with $12 \mu \mathrm{M}$ sodium nitroprusside $\left(P=0.18, \mathrm{~F}_{\text {stat }}=2.06, \mathrm{df}=13\right)$. Across all experimental samples, no correlation was observed between the maximal relaxation and precontraction tension $(P=0.82$, $\left.\mathrm{F}_{\text {stat }}=0.05, \mathrm{df}=21\right)$ or wet tissue weight $\left(P=0.33, \mathrm{~F}_{\text {stat }}=0.98\right.$, $\mathrm{df}=21)$.

\section{Discussion}

\section{Liposome characterization}

The characteristics of NOBLs can be compared directly with previously reported data on $\mathrm{C}_{3} \mathrm{~F}_{8}$-loaded bubble liposomes manufactured using similar methods. Endo-Takahashi et $\mathrm{al}^{34}$ reported a volume-weighted size distribution peak at $749 \mathrm{~nm}$ with a significant volume-weighted population greater than $4 \mu \mathrm{m}$. The bubble liposomes of Endo-Takahashi et a $\mathrm{l}^{34}$ containing only $\mathrm{C}_{3} \mathrm{~F}_{8}$, are smaller than the NOBLs described in this study (Figure 6A). NOBLs have a bimodal volume-weighted size distribution with a primary peak at $2.5 \mu \mathrm{m}$ and variable, secondary peak at $11 \mu \mathrm{m}$. This size distribution has implications for clinical translation: nanosized NOBLs are small enough to pass through the pulmonary capillary bed ${ }^{41}$ yet large enough to permit strong cavitation nucleation from $1 \mathrm{MHz}$ ultrasound exposure. ${ }^{7}$ In future studies, subpopulations of the bimodal distribution could 


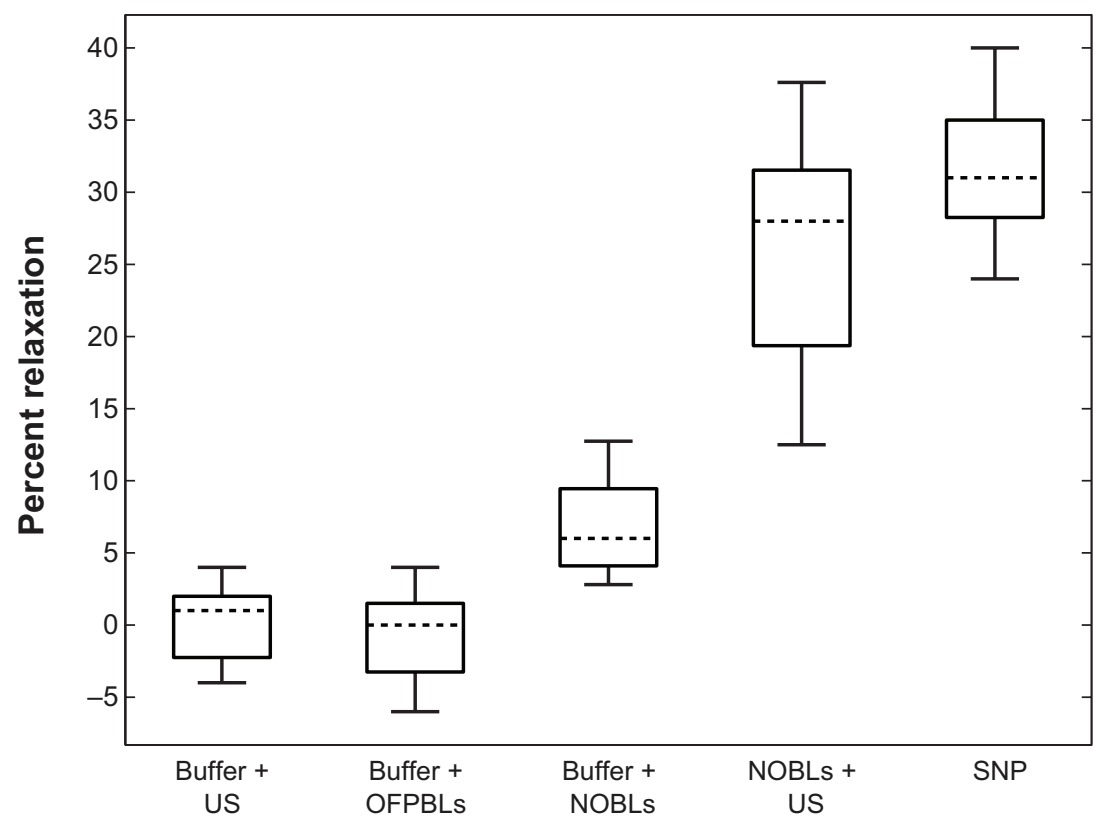

Figure 8 Carotid artery vasorelaxation as a function of treatment.

Notes: Data means are indicated by horizontal dotted lines and boxes indicate the 25 th and 75 th percentiles. The range of adjacent data is indicated by error bars. Seven arterial rings from seven pigs were used for all treatments. Statistically significant differences in data means $(\boldsymbol{P}<0.05)$ were observed between all data sets except $(\mathbf{A})$ buffer + US/buffer + OFPBL and (B) NOBLs + US/SNP.

Abbreviations: SNP, $12 \mu \mathrm{M}$ sodium nitroprusside; US, ultrasound; NOBLs, nitric-oxide loaded bubble liposomes; OFPBL, octafluoropropane-loaded bubble liposomes.

be isolated by differential centrifugation ${ }^{42}$ to avoid undesired retention in micron-sized capillaries. However, these techniques present a trade-off between frequency-dependent ultrasound response and drug-loading capability, which are both highly dependent on particle size. ${ }^{43}$

The size discrepancy between the primary peaks could be explained by the use of a NO/ $\mathrm{C}_{3} \mathrm{~F}_{8}$ blend in this study, compared with $\mathrm{C}_{3} \mathrm{~F}_{8}$ alone used in the report by Endo-Takahashi et al. ${ }^{34} \mathrm{NO}$ is more soluble in lipid than in aqueous solution, ${ }^{44}$ yet reacts more readily with oxygen in these environments. NO is further soluble in perfluorocarbon, demonstrated by prolonged release profiles in an in vivo hamster model. ${ }^{45}$ In this study, efforts were made to ensure that the procedure used to manufacture $\mathrm{NO}$ /octafluoropropaneloaded liposomes mimicked closely the procedure outlined by Endo-Takahashi et al. ${ }^{34} \mathrm{Kim}$ et al describe an alternative method to encapsulate NO within echogenic liposomes which minimizes oxidation and degradation of NO prior to experimental use ${ }^{46}$ Future work should implement these procedures and tailor the gas and lipid composition in NOBL formulations to achieve an optimal release profile and size distribution to improve therapeutic benefit.

Using this liposomal formulation, the pharmacokinetics of NOBLs in vivo are unclear. The peak number density of NOBLs occurred at $600 \mathrm{~nm}$, which was the lower limit of size detection used here. Particles in this size range, capable of retention within tumor vasculature, ${ }^{47}$ can effectively attenuate ultrasound at theragnostic frequencies. ${ }^{48}$ Further, DOTAP, a cationic lipid, likely conferred an affinity to the anionic endothelial glycocalyx. ${ }^{49}$ This strong affinity for the vascular walls would decrease circulation time in vivo, ${ }^{50}$ possibly necessitating local infusion, which would limit the applicability of NOBLs to tissues downstream from traditional intra-arterial access sites. Enhanced targeting and localization near the endothelium could also be achieved ultrasonically by use of acoustic pulses to optimize radiation force ${ }^{51}$ and acoustic streaming. ${ }^{52}$ The presence of long chain (PEG 2000) and short chain (PEG 500) polyethylene glycol has been used in liposomal formulations to mitigate potential immunogenicity and antigenicity, thus prolonging circulation time. ${ }^{53}$ In our model, bubble liposomes were injected directly into the lumen of the arterial ring, where they were exposed to 30 cycle pulses of $1 \mathrm{MHz}$ ultrasound at a peak-to-peak acoustic pressure amplitude of $0.34 \mathrm{MPa}$. Hemoglobin at in vivo concentrations would completely quench $\mathrm{NO}$ produced within the lumen of a blood vessel, thus necessitating NO delivery in close proximity to the endothelium. ${ }^{15,54}$ Future studies investigating ultrasound-mediated $\mathrm{NO}$ release from liposomes should consider these issues.

\section{Ultrasound exposure and cavitation}

The data presented here demonstrate that strong relaxation by NO-loaded liposomes can be enhanced by ultrasound exposure at acoustic pressures lower than previously 
described. ${ }^{46,55}$ In this study, vascular relaxation was triggered from NOBLs with pulsed ultrasound at a peak-to-peak acoustic pressure amplitude of $0.34 \mathrm{MPa}$. Despite the detection of strong cavitation at this acoustic pressure, the precise mechanism of NO release and delivery remains unclear. Smith et al describe acoustically driven diffusion at moderate acoustic pressures, ${ }^{56,57}$ and other investigators ${ }^{7,58,59}$ have postulated that the lipid shell of microbubbles must first be ruptured before cavitation nucleation can occur, liberating encapsulated gas during rapid fragmentation. At a $0.34 \mathrm{MPa}$ pressure exposure, it is likely that NO was released from the bubble liposomes gradually over a number of acoustic cycles. Radhakrishnan et $\mathrm{al}^{60}$ have detected loss of echogenicity from contrast agents at acoustic pressures below the stable and inertial cavitation thresholds. In their experiments using Definity ${ }^{\circledR}$ and echogenic liposomes, the onset of stable and inertial cavitation was concomitant with an $80 \%$ loss of echogenicity. Thus, the release of NO from bubble liposomes could also occur at acoustic peak-to-peak pressures lower than the $0.34 \mathrm{MPa}$ utilized in the present study. The minimum pressure amplitude that triggers the delivery of NO to vascular tissue warrants further elucidation.

In this study, $\mathrm{C}_{3} \mathrm{~F}_{8}$ stabilized $\mathrm{NO}$ within the bubble liposomes prior to activation by ultrasound. The different properties of these gases (eg, molecular size, solubility) could promote a differential diffusion profile during acoustically driven oscillation. Upon membrane distention during volumetric bubble expansion, NO would likely dissolve more readily in the surrounding aqueous medium due to its high solubility. Also, after liberation of $\mathrm{NO}$, the residual $\mathrm{C}_{3} \mathrm{~F}_{8}$ bubble activity could promote microstreaming and enhanced convection and penetration into nearby vascular tissue. The diffusivity of NO, roughly $3,300 \mu \mathrm{m}^{2}$ per second in muscular tissue, ${ }^{24,54,61}$ is high enough to support a linear diffusion distance of roughly $250 \mu \mathrm{m}$ (approximate radial depth of porcine carotid smooth muscle cells ${ }^{11,62}$ ) over several seconds. NOBL infusions with ultrasound exposure consistently caused sharp decreases in vascular tension, typically occurring in the order of tens of seconds, followed by a steady tension restoration period, which lasted several minutes (Figure 5).

\section{Vasorelaxation}

Arterial segments relaxed significantly more when treated with NOBL infusions in the presence of pulsed ultrasound, compared with infusions with NOBLs alone (Figure 8). The ability of ultrasound to promote the delivery of encapsulated NO to vascular tissue agrees with observations by previous investigators. ${ }^{46,63,64} \mathrm{Kim}$ et $\mathrm{al}^{46}$ using NO-loaded echogenic liposomes, demonstrated increased vasodilation of rabbit carotids after exposure to $5.7 \mathrm{MHz}$ color Doppler ultrasound at a peak negative acoustic pressure of $0.35 \mathrm{MPa}$. Huang et al used a mixture of NO and argon gas to encapsulate NO and trigger effective release to porcine carotid tissue. ${ }^{55}$ In this study, the release of NO from the liposome into the surrounding medium was decreased by roughly $65 \%$ using the argon/NO mixture. At lower peak-to-peak pressure amplitudes $(<0.40 \mathrm{MPa})$, other encapsulated bioactive gases, such as xenon, have been shown to exhibit enhanced release and delivery profiles with ultrasound. ${ }^{16,56,65}$ Other studies have demonstrated the feasibility of encapsulating $\mathrm{NO}$ or NO-yielding molecules to prevent physiologic degradation. ${ }^{58,66}$ For example, McKinlay et al demonstrated strong vasorelaxation of porcine coronary rings incubated with NO bound within a porous organic metal framework. ${ }^{58}$ Consequently, future studies should focus on elucidating the mechanisms of NO release from NOBLs, so that efficient exposure protocols can be developed to translate ultrasound-mediated NO delivery into the clinic.

\section{System development}

Although the ultrasound tissue bath system is capable of providing real-time feedback on NO delivery to vascular tissue, it has a few limitations. Here, a volatile anesthetic was used to sedate the animals prior to carotid excision, which can reduce endothelium function significantly by inhibiting endothelial production of NO. ${ }^{12,24}$ Cavitation near the vascular endothelium during $\mathrm{UMDD}^{11,14,67}$ is hypothesized to liberate endothelial NO synthase from membrane-bound proteins, such as caveolin-1. ${ }^{46,63,64}$ Increased cytosolic endothelial NO synthase results in increased endothelium-derived NO, ${ }^{10,68}$ an effect likely absent in our model. Future studies should employ sedatives that do not adversely affect endothelial response, or should use abattoir-derived vascular tissue.

During arterial precontraction, porcine hemoglobin was diluted into the reservoir to a concentration of $1 \mathrm{~g} / \mathrm{L}$. At this concentration, arteries consistently re-established equilibrium contraction tension following NO-induced vasorelaxation. This was likely due to the quenching of excess NO by hemoglobin, a reaction well documented in vivo. ${ }^{16,40,65}$ Because free hemoglobin quenches NO a thousand times faster than hemoglobin within intact erythrocytes, ${ }^{60,69}$ the presence of free hemoglobin in the bath likely resulted in a weaker vasorelaxation than expected in vivo in the absence of hemolysis.

At higher hemoglobin concentrations $(>40 \mathrm{~g} / \mathrm{L})$ or in whole blood (120 g/ $\left.\mathrm{L}^{31,40}\right)$, arteries routinely experienced periodic contractions that prevented restoration of tension 
to equilibrium. This effect was likely indicative of vasospasm, which has been documented in cerebral arteries as a result of subarachnoid hemorrhage. ${ }^{12}$ While this effect was a limitation in our model, Fathi et $\mathrm{a}^{67}$ describe a potential role of NO delivery to treat cerebral tissue following subarachnoid hemorrhage. Also, using intact erythrocytes, Kim et al describe a technique to release NO from loaded echogenic liposomes within the rabbit carotid artery to reduce ischemic neurologic deficits. ${ }^{46}$ Intact, fresh erythrocytes also ensure the presence of viable oxyhemoglobin to bind $\mathrm{NO}$ efficiently. ${ }^{68}$ Future applications of this ultrasound tissue bath model should implement hemoglobin in the form of intact erythrocytes to ease the transition to possible clinical applications, such as localized ultrasound-mediated delivery of NO for arresting development of atheroma, ${ }^{1,4,13}$ induction of vascular hyperpermeability, ${ }^{1,3}$ or treatment of vasospasm after subarachnoid hemorrhage. ${ }^{68}$

The system described here also implemented an infusion of treatment combinations directly to the lumen of the vessel. This approach, while likely difficult to replicate in vivo, ensured steady replenishment of drugs and bubbles during experimental treatment, and permitted simple adaptation of a previously established tissue perfusion model. An infusion of $12 \mu \mathrm{M}$ sodium nitroprusside, directly infused into the lumen of the artery, likely only remained in the arterial lumen for a few seconds before being dispersed throughout the large reservoir filled with Krebs buffer. Together, these changes may have resulted in a much lower amount of sodium nitroprusside, and its product NO, delivered to the vascular rings compared with preparations using sodium nitroprusside in traditional tissue bath systems.

\section{Smooth muscle relaxation}

In vivo, NO-mediated modulation of smooth muscle tone is well described by two biochemical pathways: (a) stimulation of guanosine $3^{\prime}: 5^{\prime}$ cyclic monophosphate (cGMP) and adenosine $3^{\prime}: 5^{\prime}$ cyclic monophosphate and (b) direct modulation of calcium-activated, potassium channel $\left(\mathrm{K}_{\mathrm{Ca}}^{+}\right)$ permeability. ${ }^{40}$ Bolotina et al describe the effect of exogenous NO on cGMP and $\mathrm{K}_{\mathrm{Ca}}^{+}$. These authors observed that cGMP-mediated vasorelaxations from exposure to $\mathrm{NO}$ were transient in nature and concentration-dependent, as determined by quantifying maximal relaxation, ${ }^{69}$ which is the metric used here. According to Tare et al the $\mathrm{K}^{+}{ }_{\mathrm{Ca}}$ pathway can affect the temporal nature of NO-mediated vasorelaxation, an interesting future application of this novel system. Accordingly, these authors integrated vasorelaxation over time to quantify integrated relaxation. ${ }^{40}$ Due to the potential for sensitivity to the $\mathrm{K}^{+}{ }_{\mathrm{Ca}}$-dependent pathway of NO-mediated vasorelaxation, integrated relaxation could be considered as a potential metric in future applications of this system, and may assist in understanding the temporal nature of ultrasoundmediated NO release from bubble liposomes.

\section{Conclusion}

The ultrasound tissue bath system described here demonstrates a novel, effective technique to characterize ultrasound-mediated delivery of a bioactive gas to vascular tissue. Ultrasound tissue bath systems can be used to monitor UMDD in real time. The data presented demonstrate that NO can be released from bubble liposomes with $1 \mathrm{MHz}$ pulsed ultrasound exposure and deposited into vascular tissue. NO penetration into tissue causes potent vasorelaxation, which manifests as a change in isometric vascular tension. Future studies using this technique may focus on monitoring the delivery of other bioactive agents that cause vasorelaxation, such as proteins, cells, or nucleic material.

\section{Acknowledgments}

This work was supported by a grant from the National Institutes of Health (R01 HL074002) and a pilot grant from the University of Cincinnati Cardiovascular Center of Excellence. The authors gratefully acknowledge Shane Duffield (University of Cincinnati; Biomedical Engineering) for his assistance with size distribution measurements and the technical staff at the National Center for Physical Acoustics (University of Mississippi, Oxford, MS, USA) for manufacturing the custom tissue bath reservoir for ultrasound studies. The authors would also like to thank Dr Neil Weintraub (Medical College of Georgia) for useful discussions about vascular biology and implementation of the tissue bath system.

\section{Disclosure}

The authors report no conflicts of interest in this work.

\section{References}

1. Vykhodtseva N, McDannold N, Hynynen K. Progress and problems in the application of focused ultrasound for blood-brain barrier disruption. Ultrasonics. 2008;48(4):279-296.

2. Laing ST, Kim H, Kopechek JA, et al. Ultrasound-mediated delivery of echogenic immunoliposomes to porcine vascular smooth muscle cells in vivo. J Liposome Res. 2010;20(2):160-167.

3. Mukherjee D, Wong J, Griffin B, et al. Ten-fold augmentation of endothelial uptake of vascular endothelial growth factor with ultrasound after systemic administration. J Am Coll Cardiol. 2000;35(6): $1678-1686$

4. Wu J, Nyborg WL. Ultrasound, cavitation bubbles and their interaction with cells. Adv Drug Deliv Rev. 2008;60(10):1103-1116. 
5. Li T, Liu G, Li J, et al. Mechanisms of prostate permeability triggered by microbubble-mediated acoustic cavitation. Cell Biochem Biophys. 2012;64(2):147-153.

6. McDannold N, Vykhodtseva N, Hynynen K. Targeted disruption of the blood-brain barrier with focused ultrasound: association with cavitation activity. Phys Med Biol. 2006;51(4):793-807.

7. Bader KB, Holland CK. Gauging the likelihood of stable cavitation from ultrasound contrast agents. Phys Med Biol. 2013;58(1):127-144.

8. Deng CX, Xu Q, Apfel R, Holland CK. In vitro measurements of inertial cavitation thresholds in human blood. Ultrasound Med Biol. 1996;22(7):939-948.

9. Komarova Y, Malik AB. Regulation of endothelial permeability via paracellular and transcellular transport pathways. Annu Rev Physiol. 2010;72(1):463-493.

10. Durán WN, Beuve AV, Sánchez FA. Nitric oxide, S-nitrosation, and endothelial permeability. IUBMB Life. 2013;65(10):819-826.

11. Davignon J. Role of endothelial dysfunction in atherosclerosis. Circulation. 2004:109(23 Suppl 1).

12. Macdonald RL, Weir BK. A review of hemoglobin and the pathogenesis of cerebral vasospasm. Stroke. 1991;22(8):971-982.

13. James AN, Ryan JP, Parkman HP. Effects of the selective serotonin reuptake inhibitor, fluoxetine, on regional gastric contractility. Neurogastroenterol Motil. 2005;17(1):76-82.

14. Sena CM, Pereira AM, Seiça R. Endothelial dysfunction - a major mediator of diabetic vascular disease. Biochim Biophys Acta. 2013;1832(12): 2216-2231.

15. Vanhoutte PM. Endothelium-dependent contractions in arteries and veins. Blood Vessels. 1987;24(3):141-144.

16. Phillips LC, Klibanov AL, Bowles DK, Ragosta M, Hossack JA, Wamhoff BR. Focused in vivo delivery of plasmid DNA to the porcine vascular wall via intravascular ultrasound destruction of microbubbles. J Vasc Res. 2010;47(3):270-274.

17. Phillips LC, Klibanov AL, Wamhoff BR, Hossack JA. Intravascular ultrasound detection and delivery of molecularly targeted microbubbles for gene delivery. IEEE Trans Ferroelectr Freq Control. 2012;59(7): 1596-1601.

18. Mylonopoulou E, Bazán-Peregrino M, Arvanitis CD, Coussios CC. A non-exothermic cell-embedding tissue-mimicking material for studies of ultrasound-induced hyperthermia and drug release. Int J Hyperthermia. 2013;29(2):133-144.

19. Deng CX, Sieling F, Pan H, Cui J. Ultrasound-induced cell membrane porosity. Ultrasound Med Biol. 2004;30(4):519-526.

20. Weintraub NL, Joshi SN, Branch CA, Stephenson AH, Sprague RS, Lonigro AJ. Relaxation of porcine coronary artery to bradykinin. Role of arachidonic acid. Hypertension. 1994;23(6 Pt 2):976-981.

21. Doinikov AA, Bouakaz A. Theoretical investigation of shear stress generated by a contrast microbubble on the cell membrane as a mechanism for sonoporation. J Acoust Soc Am. 2010;128(1):11.

22. Ihara E, Hirano K, Derkach DN, Nishimura J, Nawata H, Kanaide H. The mechanism of bradykinin-induced endothelium-dependent contraction and relaxation in the porcine interlobar renal artery. Br J Pharmacol. 2000;129(5):943-952.

23. Sheikov N, McDannold N, Sharma S, Hynynen K. Effect of focused ultrasound applied with an ultrasound contrast agent on the tight junctional integrity of the brain microvascular endothelium. Ultrasound Med Biol. 2008;34(7):1093-1104.

24. Nakamura K, Terasako K, Toda H, et al. Mechanisms of inhibition of endothelium-dependent relaxation by halothane, isoflurane, and sevoflurane. Can J Anaesth. 1994;41(4):340-346.

25. Fan Z, Liu H, Mayer M, Deng CX. Spatiotemporally controlled single cell sonoporation. Proc Natl Acad Sci U S A. 2012;109(41): 16486-16491.

26. Kleschyov AL. Does nitric oxide mediate the vasodilator activity of nitroglycerin? Circ Res. 2003;93(9):e104-e112.

27. Sutton JT, Haworth KJ, Pyne-Geithman G, Holland CK. Ultrasoundmediated drug delivery for cardiovascular disease. Expert Opin Drug Deliv. 2013;10(5):573-592.
28. Park J, Fan Z, Deng CX. Effects of shear stress cultivation on cell membrane disruption and intracellular calcium concentration in sonoporation of endothelial cells. J Biomech. 2011;44(1):164-169.

29. Jia L, Furchgott RF. Inhibition by sulfhydryl compounds of vascular relaxation induced by nitric oxide and endothelium-derived relaxing factor. J Pharmacol Exp Ther. 1993;267(1):371-378.

30. Archer SL, Huang JM, Hampl V, Nelson DP, Shultz PJ, Weir EK. Nitric oxide and cGMP cause vasorelaxation by activation of a charybdotoxinsensitive K channel by cGMP-dependent protein kinase. Proc Natl Acad Sci U S A. 1994;91(16):7583-7587.

31. Pond WG, Mersmann HJ. Biology of the Domestic Pig. Ithaca, NY, USA: Cornell University Press; 2001.

32. Herlihy JT, Murphy RA. Length-tension relationship of smooth muscle of the hog carotid artery. Circ Res. 1973;33(3):275-283.

33. Tunstall RR, Shukla P, Grazul-Bilska A, Sun C, O'Rourke ST. MT2 receptors mediate the inhibitory effects of melatonin on nitric oxide-induced relaxation of porcine isolated coronary arteries. J Pharmacol Exp Ther. 2010;336(1):127-133.

34. Endo-Takahashi Y, Negishi Y, Kato Y, Suzuki R, Maruyama K, Aramaki Y. Efficient siRNA delivery using novel siRNA-loaded bubble liposomes and ultrasound. Int J Pharm. 2012;422(1-2): 504-509.

35. AIUM Technical Standards Committee. Methods for Specifying Acoustic Properties of Tissue Mimicking Phantoms and Objects. Laurel, MD, USA: American Institute of Ultrasound in Medicine; 1995.

36. Raymond JL, Haworth KJ, Bader BK, et al. Broadband attenuation measurements of phospholipid-shelled ultrasound contrast agents. Ultrasound Med Biol. 2014;(40)2:410-421.

37. Thomas DD, Liu X, Kantrow SP, Lancaster JR. The biological lifetime of nitric oxide: implications for the perivascular dynamics of $\mathrm{NO}$ and $\mathrm{O}_{2}$. Proc Natl Acad Sci US A. 2001;98(1):355-360.

38. Hitchcock KE, Ivancevich NM, Haworth KJ, et al. Ultrasound-enhanced rt-PA thrombolysis in an ex vivo porcine carotid artery model. Ultrasound Med Biol. 2011;37(8):1240-1251.

39. Datta S, Coussios C-C, Ammi AY, Mast TD, de Courten-Myers GM, Holland CK. Ultrasound-enhanced thrombolysis using Definity as a cavitation nucleation agent. Ultrasound Med Biol. 2008;34(9): 1421-1433.

40. Tare M, Parkington HC, Coleman HA. EDHF, NO and a prostanoid: hyperpolarization-dependent and -independent relaxation in guinea-pig arteries. Br J Pharmacol. 2000;130(3):605-618.

41. Redenbach DM, English D, Hogg JC. The nature of leukocyte shape changes in the pulmonary capillaries. Am J Physiol. 1997;273(4 Pt 1): L733-L740.

42. Feshitan JA, Chen CC, Kwan JJ, Borden MA. Microbubble size isolation by differential centrifugation. J Colloid Interface Sci. 2009;329(2): 316-324.

43. Martin KH, Dayton PA. Current status and prospects for microbubbles in ultrasound theranostics. Wiley Interdiscp Rev Nanomed Nanobiotechnol. 2013;5(4):329-345.

44. Liu X, Miller MJ, Joshi MS, Thomas DD, Lancaster JR. Accelerated reaction of nitric oxide with $\mathrm{O} 2$ within the hydrophobic interior of biological membranes. Proc Natl Acad Sci U S A. 1998;95(5): 2175-2179.

45. Ortiz D, Cabrales P, Briceño JC. Transport of nitric oxide by perfluorocarbon emulsion. Biotechnol Prog. 2013;29(6):1565-1572.

46. Kim H, Britton GL, Peng T, Holland CK, Mcpherson DD, Huang S-L. Nitric oxide-loaded echogenic liposomes for treatment of vasospasm following subarachnoid hemorrhage. Int J Nanomedicine. 2014;9: 155-165.

47. Yuan F, Dellian M, Fukumura D, et al. Vascular permeability in a human tumor xenograft: molecular size dependence and cutoff size. Cancer Res. 1995;55(17):3752-3756.

48. Casciaro S, Conversano F, Ragusa A, et al. Optimal enhancement configuration of silica nanoparticles for ultrasound imaging and automatic detection at conventional diagnostic frequencies. Invest Radiol. 2010; 45(11):715-724. 
49. Van Teeffelen JW, Brands J, Stroes ES, Vink H. Endothelial glycocalyx: sweet shield of blood vessels. Trends Cardiovasc Med. 2007;17(3): 101-105.

50. Ho EA, Ramsay E, Ginj M, et al. Characterization of cationic liposome formulations designed to exhibit extended plasma residence times and tumor vasculature targeting properties. J Pharm Sci. 2010;99(6): 2839-2853.

51. Dayton P, Klibanov A, Brandenburger G, Ferrara K. Acoustic radiation force in vivo: A mechanism to assist targeting of microbubbles. Ultrasound Med Biol. 1999;25(8):1195-1201.

52. Wu J, Du G. Acoustic streaming generated by a focused Gaussian beam and finite amplitude tonebursts. Ultrasound Med Biol. 1993;19(2): 167-176.

53. Jokerst JV, Lobovkina T, Zare RN, Gambhir SS. Nanoparticle PEGylation for imaging and therapy. Nanomedicine. 2011;6(4): 715-728.

54. Lancaster JR. A tutorial on the diffusibility and reactivity of free nitric oxide. Nitric Oxide. 1997;1(1):18-30.

55. Huang SL, Kee PH, Kim H, et al. Nitric oxide-loaded echogenic liposomes for nitric oxide delivery and inhibition of intimal hyperplasia. J Am Coll Cardiol. 2009;54(7):652-659.

56. Britton GL, Kim H, Kee PH, et al. In vivo therapeutic gas delivery for neuroprotection with echogenic liposomes. Circulation. 2010;122(16): $1578-1587$.

57. Smith DAB, Porter TM, Martinez J, et al. Destruction thresholds of echogenic liposomes with clinical diagnostic ultrasound. Ultrasound Med Biol. 2007;33(5):797-809.

58. McKinlay AC, Xiao B, Wragg DS, Wheatley PS, Megson IL, Morris RE. Exceptional behavior over the whole adsorption-storage-delivery cycle for NO in porous metal organic frameworks. J Am Chem Soc. 2008;130(31):10440-10444.

59. Stride E, Saffari N. Microbubble ultrasound contrast agents: a review. Proc Inst Mech Eng H. 2003;217(6):429-447.
60. Radhakrishnan K, Bader KB, Haworth KJ, et al. Relationship between cavitation and loss of echogenicity from ultrasound contrast agents. Phys Med Biol. 2013;58(18):6541-6563.

61. Malinski T, Taha Z, Grunfeld S, Patton S, Kapturczak M, Tomboulian P. Diffusion of nitric oxide in the aorta wall monitored in situ by porphyrinic microsensors. Biochem Biophys Res Commun. 1993;193(3): 1076-1082.

62. Groves PH, Banning AP, Penny WJ, Lewis MJ, Cheadle HA, Newby AC. Kinetics of smooth muscle cell proliferation and intimal thickening in a pig carotid model of balloon injury. Atherosclerosis. 1995;117(1): 83-96.

63. Sheikov N, McDannold N, Vykhodtseva N, Jolesz F, Hynynen K. Cellular mechanisms of the blood-brain barrier opening induced by ultrasound in presence of microbubbles. Ultrasound Med Biol. 2004;30(7): 979-989.

64. Deng J, Huang Q, Wang F, et al. The role of caveolin-1 in bloodbrain barrier disruption induced by focused ultrasound combined with microbubbles. J Mol Neurosci. 2011;46(3):677-687.

65. Owusu BY, Stapley R, Patel RP. Nitric oxide formation versus scavenging: the red blood cell balancing act. J Physiol (Lond). 2012;590(20): 4993-5000.

66. Donadee C, Raat NJH, Kanias T, et al. Nitric oxide scavenging by red blood cell microparticles and cell-free hemoglobin as a mechanism for the red cell storage lesion. Circulation. 2011;124(4):465-476.

67. Fathi AR, Bakhtian KD, Pluta RM. The role of nitric oxide donors in treating cerebral vasospasm after subarachnoid hemorrhage. Acta Neurochir Suppl. 2011;110 Pt 1:93-97.

68. Beckman JS, Koppenol WH. Nitric oxide, superoxide, and peroxynitrite: the good, the bad, and ugly. Am J Physiol. 1996;271(5 Pt 1): C1424-C1437.

69. Bolotina VM, Najibi S, Palacino JJ, Pagano PJ, Cohen RA. Nitric oxide directly activates calcium-dependent potassium channels in vascular smooth muscle. Nature. 1994;368(6474):850-853.
International Journal of Nanomedicine

\section{Publish your work in this journal}

The International Journal of Nanomedicine is an international, peerreviewed journal focusing on the application of nanotechnology in diagnostics, therapeutics, and drug delivery systems throughout the biomedical field. This journal is indexed on PubMed Central, MedLine, CAS, SciSearch $®$, Current Contents $\AA /$ Clinical Medicine,

\section{Dovepress}

Journal Citation Reports/Science Edition, EMBase, Scopus and the Elsevier Bibliographic databases. The manuscript management system is completely online and includes a very quick and fair peer-review system, which is all easy to use. Visit http://www.dovepress.com/ testimonials.php to read real quotes from published authors. 